\title{
Inhibition of retinoic acid receptor a phosphorylation represses the progression of triple-negative breast cancer via transactivating miR-3074-5p to target DHRS3
}

Siyue Lou ${ }^{*+}$, Hang Gao ${ }^{\dagger}$, Huanwu Hong, Zhihui Zhu and Huajun Zhao ${ }^{*}$

\begin{abstract}
Background: Retinoids are promising agents in the treatment of different types of neoplasia including estrogen receptor-positive breast cancers, whereas refractoriness/low sensitivity is observed in triple-negative breast cancer (TNBC) subtype. However, the reason for these diverse retinoid-sensitivity remains elusive.

Methods: Determinants of retinoid sensitivity were investigated using immunohistochemistry of primary patient samples, and identified retinoic acid receptor a (RARa) as a putative factor. The anti-tumor activity of hypophosphorylated RARa was investigated in TNBC cell models and a xenograft mouse model. Next, miRNA sequencing analysis was performed to identify the target miRNA of RARa, and luciferase reporter was used to confirm the direct target gene of miR-3074-5p.

Results: We discovered that serine-77 residue of RARa was constantly phosphorylated, which correlated with TNBC's resistance to retinoids. Overexpression of a phosphorylation-defective mutant RARaS77A mimicked activated RARa and repressed TNBC cell progression both in vitro and in vivo, via activating cell cycle arrest, apoptosis, and cytotoxic autophagy, independent of RARa agonists. We further revealed that the anti-tumor action of RARaS77A was, at least in part, mediated by the up-regulation of miR-3074-5p, which directly targeted DHRS3, a reductase negatively associated with TNBC patient survival. Our results suggest that the inhibition of RARaS77 phosphorylation by either expressing RARaS77A or inhibiting RARa's phosphokinase CDK7, can bypass RA stimuli to transactivate tumor-suppressive miR-3074-5p and reduce oncogenic DHRS3, thus overcoming the RA-resistance of TNBC.

Conclusion: The novel regulatory network, involving RARaS77 phosphorylation, miR-3074-5p, and DHRS3, emerges as a new target for TNBC treatment.
\end{abstract}

Keywords: RARa, Triple-negative breast cancer, Phosphorylation, miR-3074-5p, DHRS3

\footnotetext{
*Correspondence: Isy@zcmu.edu.cn; zhj@zcmu.edu.cn

†'Siyue Lou and Hang Gao contributed equally to this work.

School of Pharmaceutical Sciences, Zhejiang Chinese Medical University,

\#548 Binwen Road, Hangzhou 310053, China
}

(c) The Author(s). 2021 Open Access This article is licensed under a Creative Commons Attribution 4.0 International License, which permits use, sharing, adaptation, distribution and reproduction in any medium or format, as long as you give appropriate credit to the original author(s) and the source, provide a link to the Creative Commons licence, and indicate if changes were made. The images or other third party material in this article are included in the article's Creative Commons. licence, unless indicated otherwise in a credit line to the material. If material is not included in the article's Creative Commons licence and your intended use is not permitted by statutory regulation or exceeds the permitted use, you will need to obtain permission directly from the copyright holder. To view a copy of this licence, visit http://creativecommons.org/licenses/by/4.0/. The Creative Commons Public Domain Dedication waiver (http://creativecommons.org/publicdomain/zero/1.0/) applies to the data made available in this article, unless otherwise stated in a credit line to the data. 


\section{Background}

Triple-negative breast cancer (TNBC) is a heterogeneous disease characterized by a lack of estrogen receptor (ER), progesterone receptor (PR), and HER2, and comprise approximately $15-20 \%$ of breast cancers [1]. They represent a challenge clinically due to the lack of targeted therapies coupled with an aggressive disease course, leaving cytotoxic chemotherapy and radiotherapy as the mainstay of treatment [2], thus driving research to find better therapeutics to improve the outcomes for this subtype.

All-trans retinoic acid (ATRA or RA) is the most potent natural form of vitamin A. It inhibits proliferation and induces differentiation/apoptosis in a variety of cancer cells and holds great promise as a chemotherapeutic agent [3-5], especially in the treatment of acute promyelocytic leukemia (APL) [6-8]. However, in breast carcinoma cells, only luminal and ER+ subtype are considered sensitive to retinoids $[9,10]$, while the majority of TNBC are unresponsive to RA treatment [10]. Therefore, comprehensive studies into the mechanism of RA-resistance may find alternative ways to bypass RA stimuli and offer novel therapies to treat these refractory breast cancers.

The canonical action of RA is exerted by its binding and activating nuclear retinoic acid receptors $R A R \alpha, \beta$, and $\gamma$. RAR dimerizes with retinoid-X-receptor (RXR) and regulates transcription of genes with retinoic acid response element (RARE) sequences in their promoters [3-5]. Among RAR subunits, RAR $\alpha$ is the principal mediator of RA responsiveness in breast cancer [10]. As a phosphoprotein, RAR $\alpha$ is a substrate of the cyclindependent kinase-activating kinase (CAK) complex consisting of CDK7 [11], cyclin H [12], and MAT1 [13, 14]. Ser-77 located at the AF-1 domain of RAR $\alpha$ (RAR $\alpha$ S77) is the main residue phosphorylated by CAK $[15,16]$. Previous studies have shown that hyper-phosphorylation of RAR $\alpha$ by CAK is associated with increased proliferation of acute myeloid leukemia (AML) and other types of cancer cells, whereas RA-induced RAR $\alpha$ hypophosphorylation or mimicked hypo-phosphorylation by expressing RAR $\alpha$ S77A mutant inhibited proliferation of cancer cells [17-21]. Of note, when expressing RAR $\alpha$ and RAR $\alpha$ S77A in parallel in RA-resistant AML cell line harboring a defective RAR $\alpha$ ligand binding domain or in embryonic teratocarcinoma $\mathrm{RAR}^{-/-}$stem cells, RAR$\alpha$ S77A, but not RAR $\alpha$, inhibited proliferation without a need of RA stimulation [21]. These findings suggest that hypo-phosphorylated RAR $\alpha \mathrm{S} 77$ may overcome RAresistance and functions as an activated form of RAR $\alpha$. However, the correlation between phosphorylation level of RAR $\alpha$ S77 and RA-resistance, as well as the effects of RAR $\alpha$ S77A in breast cancer cells, remains unknown.

MicroRNAs (miRNAs) are a class of endogenous small noncoding RNAs that regulate gene expression post- transcriptionally by binding to their target mRNAs for degradation and/or translational repression [22]. Dysregulated miRNAs are involved in several cellular processes of TNBC, exerting their function as either oncogenes or tumor suppressor genes [23]. Recent evidence indicates that several miRNAs can be modulated by nuclear receptors such as RAR $\alpha$ [24]. By binding to RARE regions of target genes, RAR $\alpha$ can regulate miR-10a [25] and miR-21 [9] transcription to participate in proliferation and motility of tumor cells. However, the function and role of miRNAs in TNBC are still not fully understood, and no study has demonstrated whether hypophosphorylated RAR $\alpha$ S77 is equally capable of regulating transcription of miRNA as that of RAR $\alpha$.

We show here that RAR $\alpha$ S77 hyper-phosphorylation contributes to RA-resistance and tumor progression of TNBC by transcriptional suppression of miR-3074-5p, thus suggesting the RAR $\alpha / m i R-3074-5 p / D H R S 3$ axis may serve as novel therapeutic targets for TNBC.

\section{Materials and methods \\ Chemicals and reagents}

DMSO, DAPI, and MTT were purchased from SigmaAldrich (St. Louis, MO, USA). Propidium iodide (PI)/ RNase staining kit and Annexin V-APC/7-AAD kit were purchased from Becton Dickinson (San Diego, CA, USA). The TUNEL kit was purchased from Yeasen Biotech (Shanghai, China). 3-MA was purchased from Selleckchem (Houston, TX, USA). ATRA, AM80, AM580, and THZ-1 were purchased from MedChemExpress (Monmouth Junction, NJ, USA). Antibody information is detailed in Supplemental Methods.

\section{Cell lines and cell culture}

Human breast cancer cell lines were purchased from the cell bank of Shanghai Institute of Materia Medica, Chinese Academy of Sciences (Shanghai, China). Human embryonic kidney cells 293FT cells were purchased from National Infrastructure of Cell Line Resource (Beijing, China). TNBC cells were cultured in L15 medium, whereas other breast cancer cells were cultured in DMEM medium. 293FT cells were cultured in DMEMhigh glucose medium (Gibco, NY, USA). All culture medium was supplemented with $10 \%$ fetal bovine serum (Gibco), penicillin (100 U/mL), and streptomycin $(100 \mu \mathrm{g} / \mathrm{mL})$.

\section{Primary specimens and tissue microarrays}

Tumorous and their adjacent non-tumorous TNBC tissues were collected from 10 patients who underwent surgery at Zhejiang Cancer Hospital. Written informed consent was obtained from each patient and the study protocol conformed to the ethical guidelines of the 1975 Declaration of Helsinki and was approved by the 
Institute Research Ethics Committee of the Zhejiang Cancer Hospital. Details of tissue microarrays (TMA) immune-staining and scoring methods are given in the Supplemental Methods.

\section{Immunohistochemistry (IHC) analysis}

Immunohistochemistry (IHC) analysis was performed as described [26]. Further details are given in the Supplemental Methods.

\section{Plasmid construction, transfection, and lentiviral production}

The pcDNA3.0-RAR $\alpha$ and pLVX-AcGFP-N1-RAR $\alpha$ plasmids were purchased from Shanghai Nuoyue Biotechnology Co., Ltd. The p-Enter-DHRS3 plasmid was purchased from Vigene biosciences (Shandong, China). The pcDNA3.0-RAR $\alpha$ S77A, pLVX-AcGFP-N1RAR $\alpha$ S77A, and p-Enter-DHRS3-Y188H were constructed using QuickMutation $^{\mathrm{TM}}$ Plus gene site-directed mutation Kit (Beyotime, Shanghai, China). Plasmid transfection and lentiviral production were performed as described [20], with minor modifications detailed in the Supplemental Methods.

\section{Colony formation and cell viability assay}

Colony formation and cell viability assay were performed as described previously [27]. Details are given in the Supplemental Methods.

\section{Western blotting (WB), cell cycle, and cell apoptosis analysis}

WB, cell cycle, and apoptosis analysis were performed as described [27], and detailed in the Supplemental Methods.

\section{Acridine orange $(\mathrm{AO})$ staining}

See details in Supplemental Methods.

\section{In vivo animal studies}

MDA-MB-231 cells $\left(2 \times 10^{6}\right.$ cells, suspended in $0.1 \mathrm{~mL}$ PBS) overexpressing either empty vector, RAR $\alpha$ S77A, or RAR $\alpha$ were injected subcutaneously into 4-week-old $\mathrm{BALB} / \mathrm{c}$ nu/nu female mice (Shanghai Experimental Animal Center, Shanghai, China). Tumor growth was measured every 3 days and tumor volume was calculated according to the formula: $1 / 2 \times$ length $\times$ width $^{2}$. After 26 days, the mice were sacrificed and the xenografts were removed for TUNEL staining and IHC analysis. All animal experiments were reviewed and approved by the Institutional Animal Care and Use Committee.

\section{TUNEL staining}

Briefly, tumor tissues were fixed in $4 \%$ paraformaldehyde, cut into $5 \mu \mathrm{m}$ sections, and stained as the manufacture's instruction. Then, the sections were immersed into DAPI staining. TUNEL-positive (red) and DAPI-positive (blue) staining patterns were acquired under a fluorescence microscope (Nikon, Japan).

\section{Expression profile analysis of miRNAs}

Total RNAs were extracted from MDA-MB-231 blank cells and RAR $\alpha$ S77A-overexpressing cells using Trizol reagent (Invitrogen, Carlsbad, CA). Comprehensive miRNA expression analysis was performed using a NEBNext $^{\oplus}$ Multiplex Small RNA Library Prep Set for Illumina ${ }^{\odot}$ and an Illumina Hiseq 2500 platform (Novogene Bioinformatics Technology Co. Ltd., Beijing, China), which detects mature miRNAs. The data has been deposited in GEO: GSE160295.

\section{RNA isolation and quantitative reverse-transcriptase PCR (qRT-PCR)}

RNA isolation and qRT-PCR analysis were performed as described [20]. The primers for targeted genes and miRNA were listed in the Supplemental Methods.

\section{miRNA mimics}

miR-3074-5p mimic/mimic-NC were purchased from Ribo Bio (Guangzhou, China). The sense and antisense sequence of miR-3074-5p mimic were GUUCCUGCUG AACUGAGCCAG and CUGGCUCAGUUCAGCAGG $\mathrm{AAC}$. The sense and antisense sequence of mimic-NC were UUUGUACUACACAAAAGUACUG and CAGUACUUUUGUGUAGUACAAA. The transfection system was the mixture of $1 \times$ riboFECTTMCP Buffer, $100 \mathrm{ng} / \mu \mathrm{l}$ riboFECTTMCP Regent, and mimic (100 nM), and the mixture was added drop-wise to the appropriate wells, respectively. Then, the medium with miRNA transfection was changed after 4-6 h.

\section{Luciferase reporter assay}

$2 \times 10^{5}$ 293FT cells were plated in 24-well for $24 \mathrm{~h}$, followed by transfection with mimic-NC or mimic-miR3074-5p, pmirGLO, wild type pmirGLO-DHRS3 3'UTR. Transfection was performed using Lipofectamine 2000 (Invitrogen, Shanghai, China) based on the manufacturer's protocol. The activities of luciferase were normalized to firefly luciferase.

\section{Statistical analysis}

All data are expressed as mean \pm SD. Statistical significance was analyzed using the Student's t-test. The criterion of statistical significance was ${ }^{*} p<0.05$; $* * 0.01$; $* * * 0<0.001$. 


\section{Results}

Constant phosphorylation of RARaS77 in human TNBC cells associates with RA-resistance

To evaluate the phosphorylation level of RAR $\alpha \mathrm{S} 77$ in TNBC, immunohistochemistry (IHC) was performed to assess the expression of RAR $\alpha$ ( $\mathrm{p}$-Ser77) protein in a set of 10 tumors and adjacent non-tumorous TNBC tissues. The expression of RAR $\alpha$ (p-Ser77) was significantly higher in TNBC specimens versus the non-tumorous tissues (Fig. 1a), thus suggesting a plausible role of RAR $\alpha \mathrm{S} 77$ phosphorylation in TNBC cells. Due to the limited number of patient samples, in order to verify if the above findings were consistent with a different analysis platform and patient cohort, we performed IHC analyses using human breast cancer tissue microarray (TMA) slides. Similar to the data obtained with the patient samples, 92\% of TNBC samples exhibited strong positive staining of RAR $\alpha$ (p-Ser77), which is significantly higher than that of non-TNBC subtypes $(p<0.001)$ (Fig. 1b), whereas no significant correlations between $\operatorname{RAR} \alpha$ (p-Ser77) and other clinicopathological variables such as patient age, lymph node status, TNM stage, and metastasis were observed (Supplemental Table 1). These results demonstrated the clinical significance of hyper-phosphorylated RAR $\alpha \mathrm{S} 77$ serving as a potential molecular target for TNBC patients.

Next, we sought to determine whether RAR $\alpha$ S77 is also phosphorylated in TNBC cell lines. RAR $\alpha$ (pSer77) expression level was detected in three TNBC cell lines (MDA-MB-231, MDA-MB-436, and MDAMB-453), MCF-7 (PR+/ER+/HER2-), T47D (PR+/ ER+/HER2-), and SKBR3 (HER2+) cells. As expected, all three TNBC cell lines exhibited phosphorylated RAR $\alpha \mathrm{S} 77$, which remained unchanged after the treatment of a selective RAR $\alpha$ agonist AM580 [28, 29], whereas the addition of AM580 reduced RAR $\alpha \mathrm{S} 77$ phosphorylation in RA-sensitive non-TNBC cell lines (Fig. 1c) [10]. This is in accordance with the previous finding that RAR $\alpha$ agonists reduced RAR $\alpha$ phosphorylation at Ser77 residue in RA-sensitive cells [21]. To determine whether the difference of RAR $\alpha$ phosphorylation levels between TNBC and non-TNBC cells is related to their sensitivity to RA, we analyzed TNBC cell proliferation after the treatment of different RARs agonists (pan-RARs agonist ATRA, RAR $\alpha / \beta$ agonist AM80, and RAR $\alpha$ agonist AM580). Unlike RAsensitive cells [10], TNBC cells showed resistance to RARs agonists, which is accompanied by the constant phosphorylation of RAR $\alpha \mathrm{S} 77$ (Fig. 1d-f, Supplemental Fig. 1). Taken together, these results indicate that the phosphorylation of RAR $\alpha \mathrm{S} 77$ is associated with RA-resistance of TNBC cells.
Phosphorylation-defective RARa-mediated suppression of TNBC cell growth in vitro is independent of ligandactivation

Previous reports indicated that RAR $\alpha$ S77A, a phosphorylation-defective mutant of RAR $\alpha$, could mimic RAR $\alpha$ hypo-phosphorylation and inhibit the proliferation of human squamous carcinoma, osteosarcoma, and AML cells [17-21]. Therefore, we wondered whether RAR $\alpha$ S77A can reverse the hyper-phosphorylated status of TNBC cells to overcome RA-resistance and induce proliferation inhibition. After transducing lentiviral RAR $\alpha$ S77A, wild-type RAR $\alpha$, and empty vector in TNBC cell lines (Supplemental Fig. 2), western blotting (WB) analysis confirmed the hypo-phosphorylation of RAR $\alpha S 77$ and overexpression of RAR $\alpha$ receptor (Fig. 2a, Supplemental Fig. 3A). MTT analysis showed that RAR$\alpha$ S77A caused a significant decrease of TNBC cell survival regardless of the addition of RAR $\alpha$ agonists, whereas overexpression of wild-type RAR $\alpha$ in the presence of RAR $\alpha$ agonists failed to induce proliferation inhibition (Fig. 2b, Supplemental Fig. 3B). Colony formation assays further proved that RAR $\alpha$ S77A reduced TNBC cell growth, independently of RAR $\alpha$ agonists (Fig. 2c-d, Supplemental Fig. 3C). Interestingly, the overexpression of RAR $\alpha$ S77A alone could activate transcription of direct RA-target genes such as p21 [30], Caspase-9 [31], C/EBPE [32], RAR $\beta_{2}$ [33], and CYP26A1 [34] (Fig. $2 \mathrm{e})$, thus suggesting that RAR $\alpha$ S77A may override RARAR $\alpha$ signaling blockade in TNBC cells. The above findings indicate that the decrease of RAR $\alpha \mathrm{S} 77$ phosphorylation, but not the level of RAR $\alpha$, is crucial for RAR $\alpha$ activation and suppression of TNBC growth in vitro.

\section{RARaS77A induces TNBC cell cycle arrest and apoptosis}

To explore the mechanism by which RAR $\alpha$ S77A inhibited proliferation of TNBC cells, cell cycle analysis was performed to test whether cells overexpressing $\mathrm{RAR} \alpha \mathrm{S} 77 \mathrm{~A}$ were arrested in a specific phase. Flow cytometric analysis showed that RAR $\alpha$ S77A induced G0/G1 arrest and a concomitant decrease of cell number at the $S$ phase, independently of RAR $\alpha$ agonist (Fig. 3a, Supplemental Fig. 4A). This is in line with the previous report that ATRA coordinates G1 arrest by inducing $\operatorname{RAR} \alpha$ hypo-phosphorylation in APL cells [35]. Consistent with the proliferation data, RAR $\alpha$ in the presence of agonist did not cause significant changes in the cell cycle. WB analysis of several cell cycle-related proteins showed that RAR $\alpha$ S77A markedly decreased the expression of Cyclin D1, CDK4, and c-Myc (Fig. 3b, Supplemental Fig. 4B). Thus, the phosphorylation status of RAR $\alpha \mathrm{S} 77$ seems to regulate $\mathrm{G} 1 / \mathrm{S}$ phase transition, while hypophosphorylated RAR $\alpha$ S77A represses cell cycle progression. 


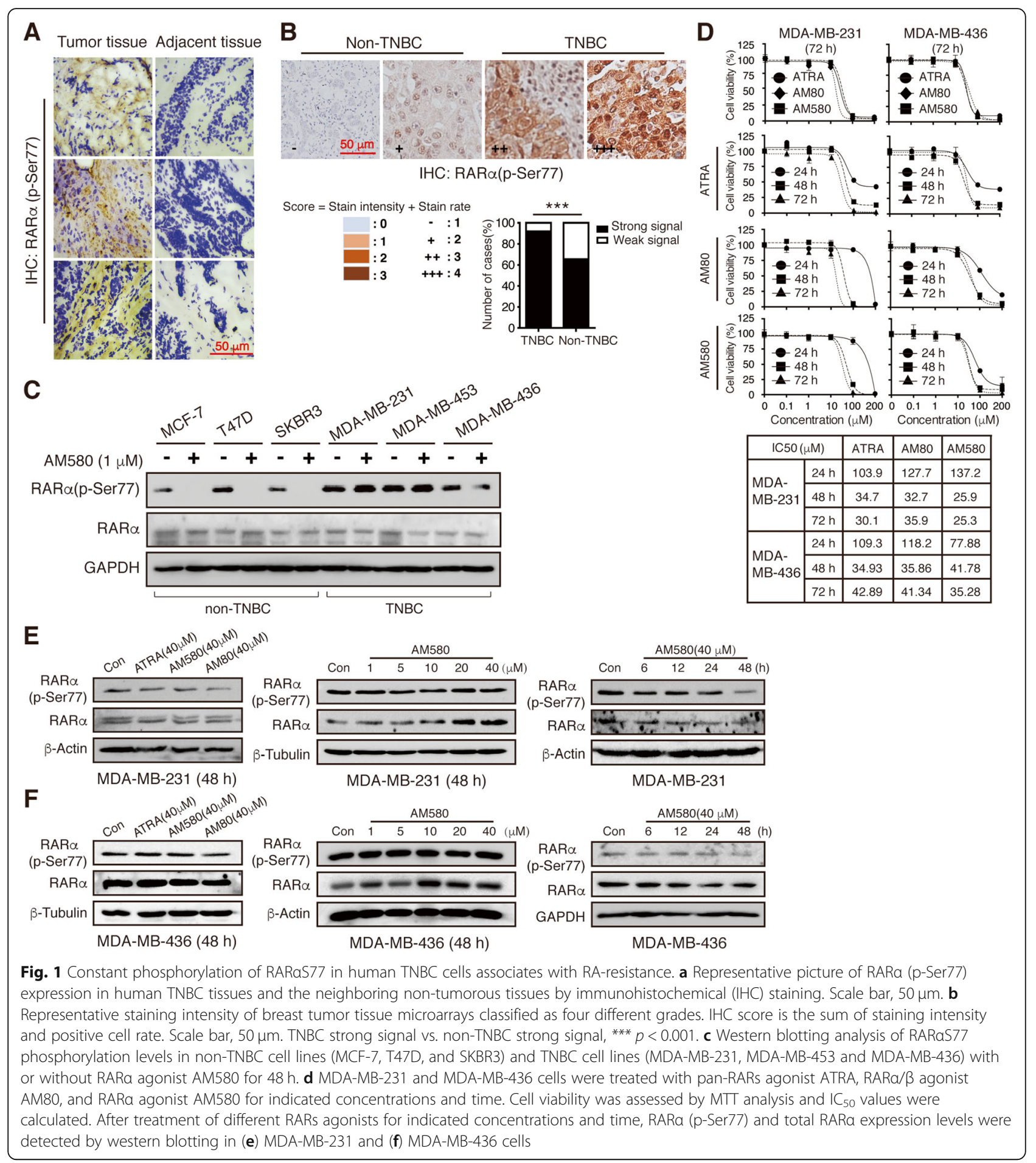

Further to determine whether RAR $\alpha$ S77A-induced proliferation inhibition may be related to apoptosis, flow cytometry analysis was performed and results showed that the expression of RAR $\alpha$ S77A promoted apoptosis in TNBC cells, regardless of the presence or absence of RAR $\alpha$ agonist (Fig. 4a, Supplemental Fig. 4C). WB analysis also confirmed the cleavage and activation of caspase $3 / 8$ and PARP (Fig. 4b, Supplemental Fig. 4d). Collectively, these data suggested that RAR $\alpha \mathrm{S} 77 \mathrm{~A}$ induces cell cycle arrest and apoptosis to inhibit TNBC cell proliferation in vitro.

RARaS77A activates cytotoxic autophagy in TNBC cells Since activation of RAR $\alpha$ induced autophagic flux in RA-sensitive but not in RA-resistant breast cancer 


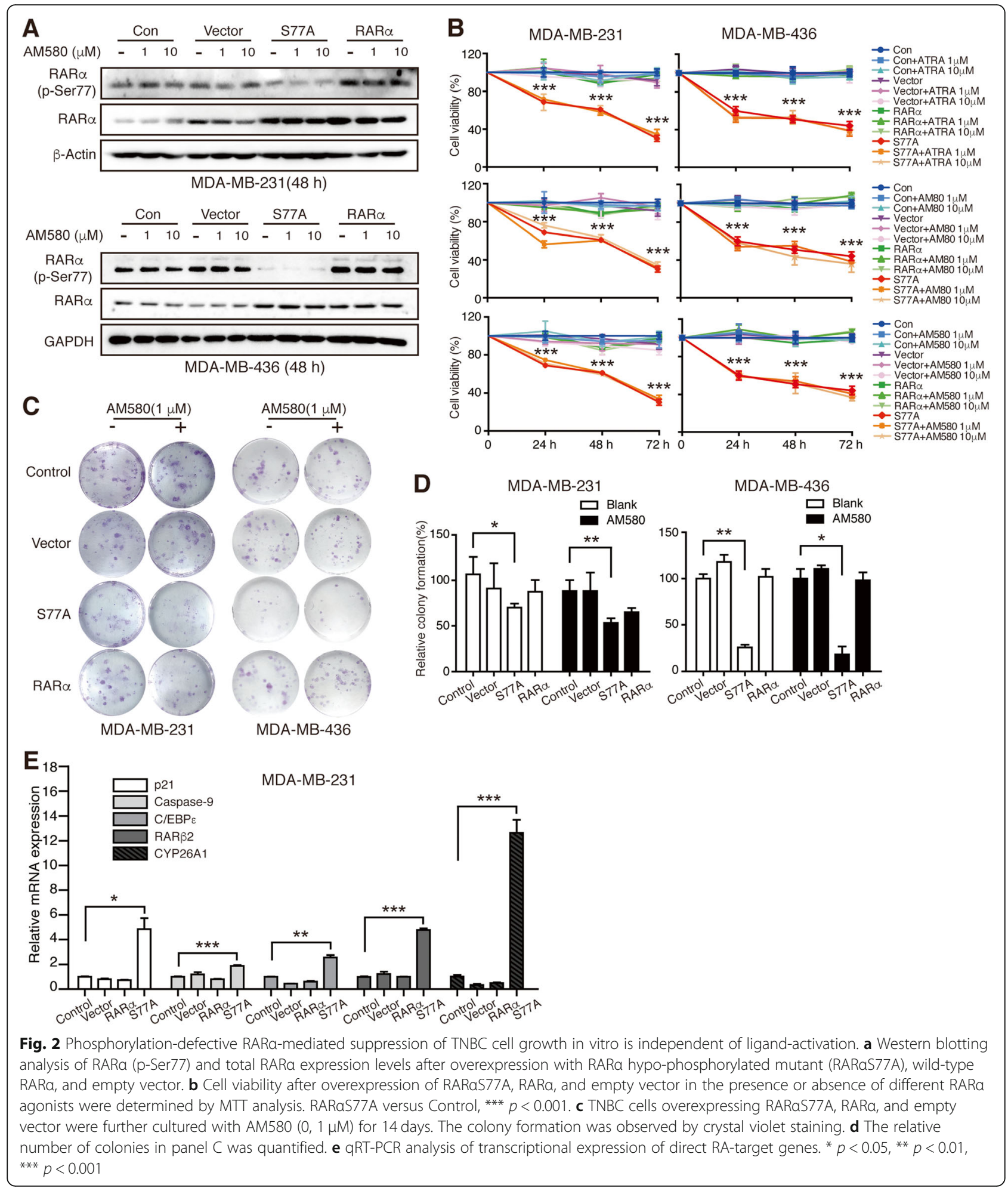

cells [36], we asked whether RAR $\alpha$ S77A could bypass RAR $\alpha$ activation to induce autophagy in TNBC cells as well. To avoid GFP interference from the lentiviral backbone, we transiently transfected pcDNA3.0vector/RAR $\alpha / R A R \alpha S 77 A$ plasmids into all three
TNBC cells (Fig. 5a), and observed an increase in the formation of acidic vesicular organelles, accompanied by elevated LC3B-II, ATG7, and decrease of p62 (Fig. 5b-c, Supplemental Fig. 5A-C). As autophagy response can be either cyto-protective or 


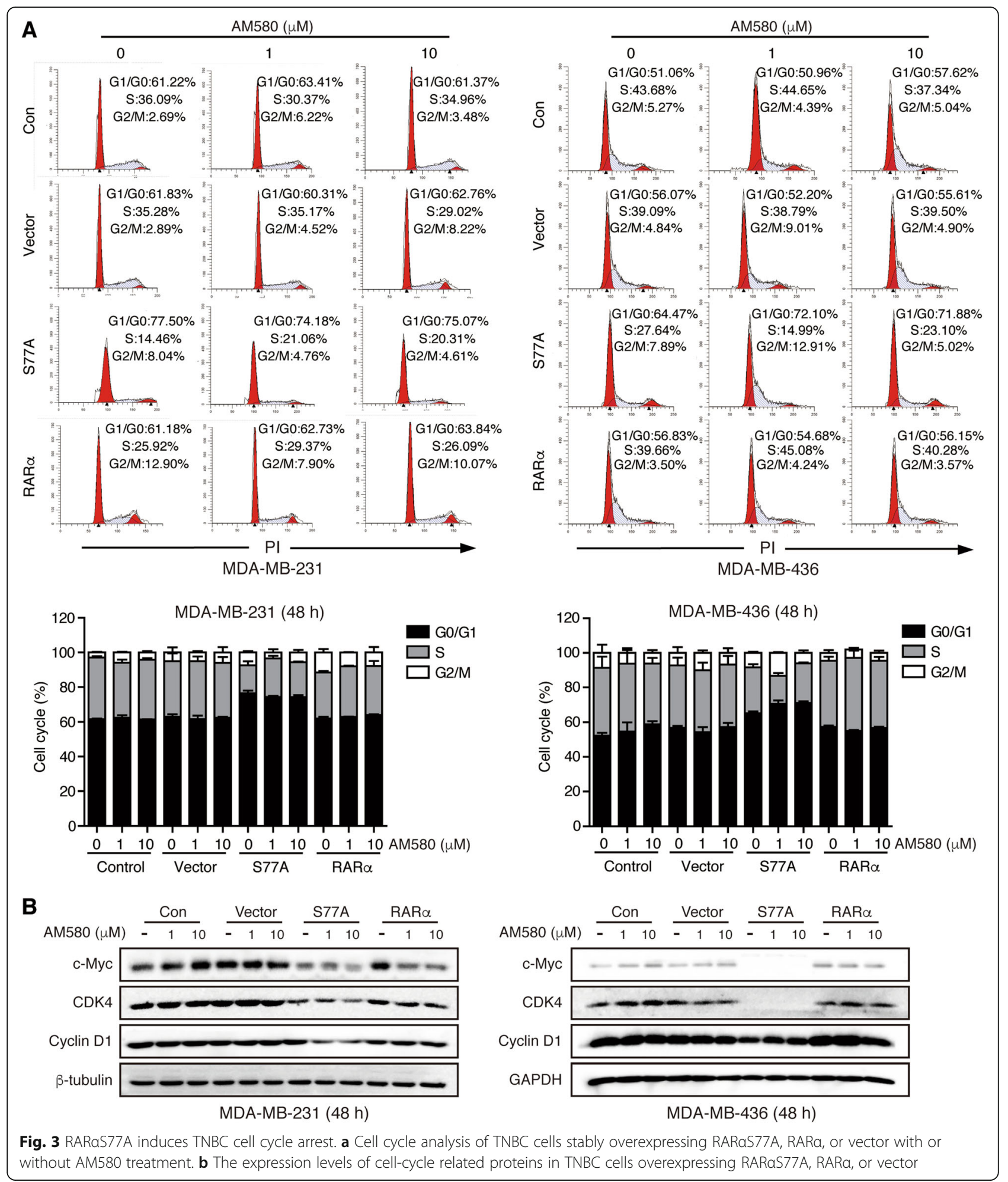

cytotoxic, we next examined the outcome of RAR $\alpha$ S77A-induced autophagy. Pre-treatment of autophagy inhibitor 3-MA partially abolished the growth inhibitory effect of RAR $\alpha$ S77A (Fig. 5d,
Supplemental Fig. 5D), thus suggesting that RAR $\alpha$ S77A-induced autophagy is cytotoxic, which may have contributed to the anti-tumor action of RAR $\alpha$ S77A. 


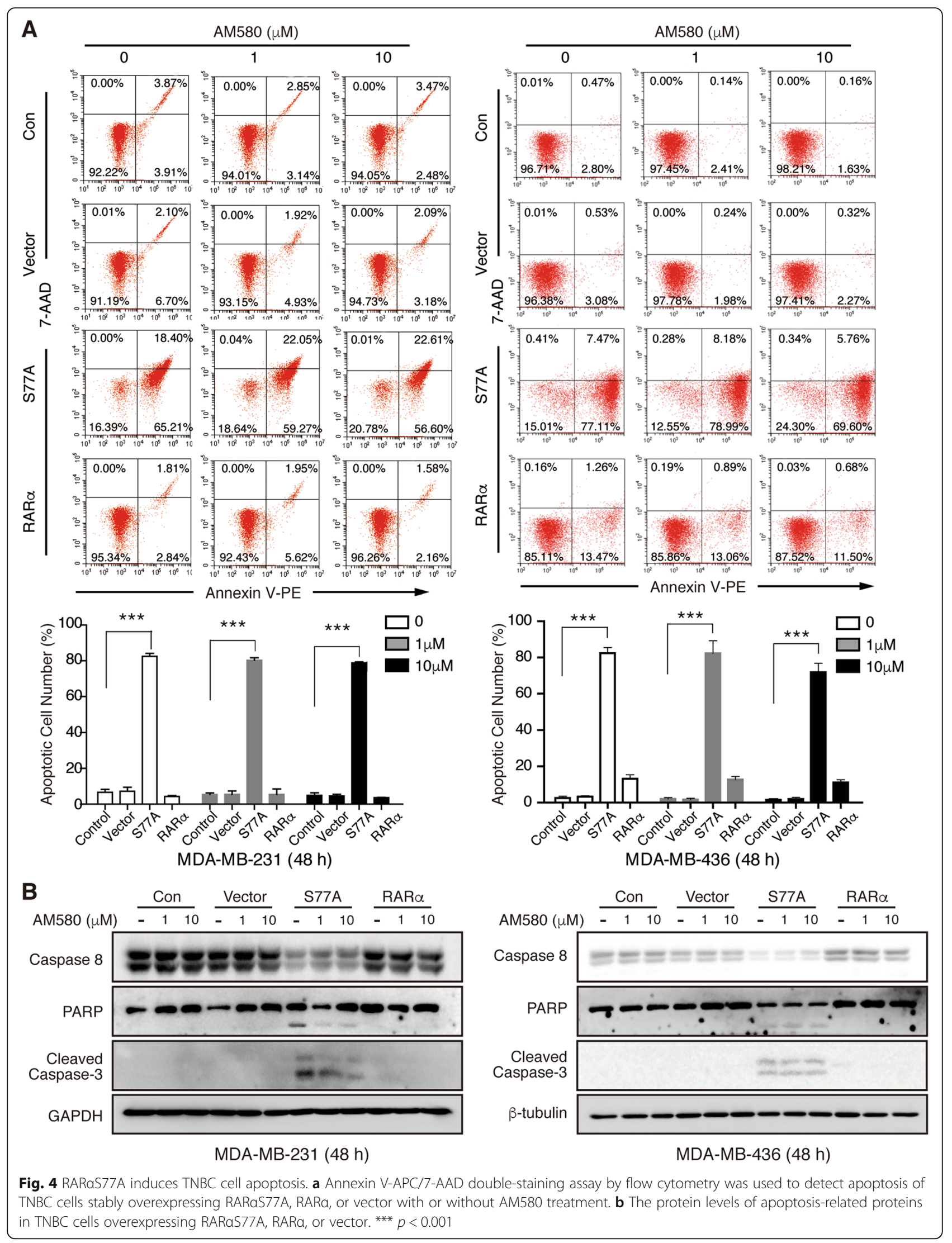




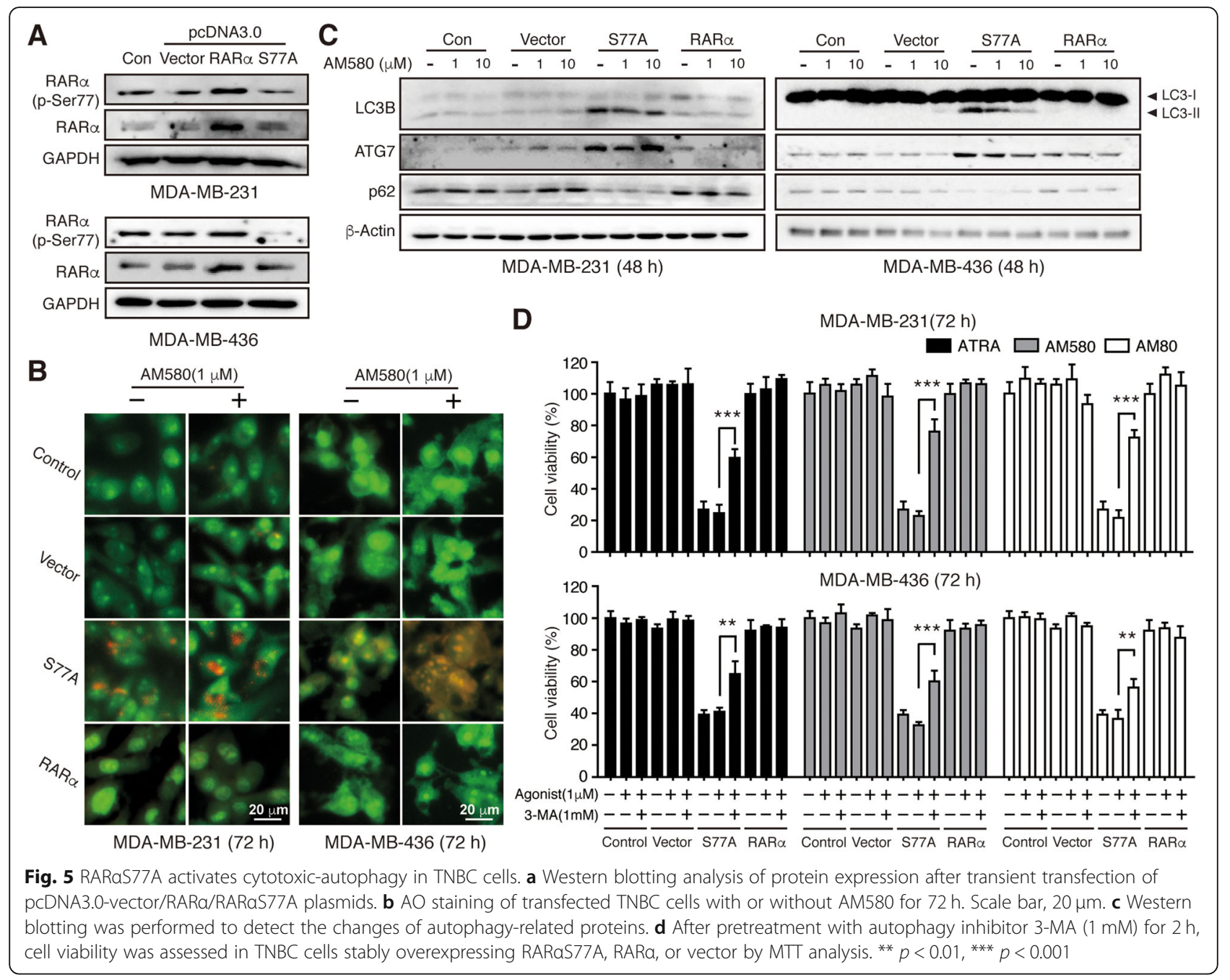

\section{RARaS77A suppresses TNBC cell growth in vivo}

To further evaluate the roles of RAR $\alpha$ S77A on tumor progression in vivo, we performed animal experiments using a nude mouse tumor xenograft model. As shown in Fig. 6a-c, tumors derived from the RAR $\alpha$ S77A cell group grew slower and resulted in a smaller size and a lighter weight than those from the control group. Consistent with the in vitro results of this study, hypophosphorylation of RAR $\alpha \mathrm{S} 77$ (Fig. 6d) induced noticeable apoptosis, along with the upregulation of p27 and LC3B expression in tumor tissue sections, as exhibited by TUNEL staining and IHC analysis (Fig. 6e-f). These results suggest that RAR $\alpha$ S77A could suppress the growth of TNBC cells in vivo via induction of apoptosis, cell cycle arrest, and autophagy.

miR-3074-5p mediates the tumor-suppressive function of RARaS77A by targeting DHRS3

Given that RAR $\alpha$ is a transcription factor that participates in regulating transcription of various genes as well as
miRNAs $[9,25]$, we were thus inspired to investigate whether the anti-tumor efficacy of RAR $\alpha$ S77A is attributed to activating transcription of functional miRNAs. We performed a miRNA sequencing analysis of MDA-MB231 cells overexpressing RAR $\alpha$ S77A. Results identified 126 up-regulated miRNAs and 144 down-regulated miRNAs, compared to control cells (Fig. 7a, Supplemental Data). Among these miRNAs, miR-3074-5p, a regulator of oncogenic cAMP-responsive element binding-protein [37], was highly expressed and validated by qRT-PCR (Fig. 7b). To explore the biological function of miR-3074-5p in TNBC, we overexpressed miR-3074-5p mimic or mimicNC in MDA-MB-231 cells. MTT analysis showed that miR-3074-5p impaired MDA-MB-231 cell growth by decreasing cell viability (Fig. $7 \mathrm{~b}$ ), thus implying a potential tumor-suppressive role of miR-3074-5p.

To explore which mRNA target of miR-3074-5p mediates the antitumor efficacy of RAR $\alpha \mathrm{S} 77 \mathrm{~A}$, candidate genes retaining miR-3074-5p-binding sequences were predicted using miRanda, miRDB, and Targetscan (Fig. 


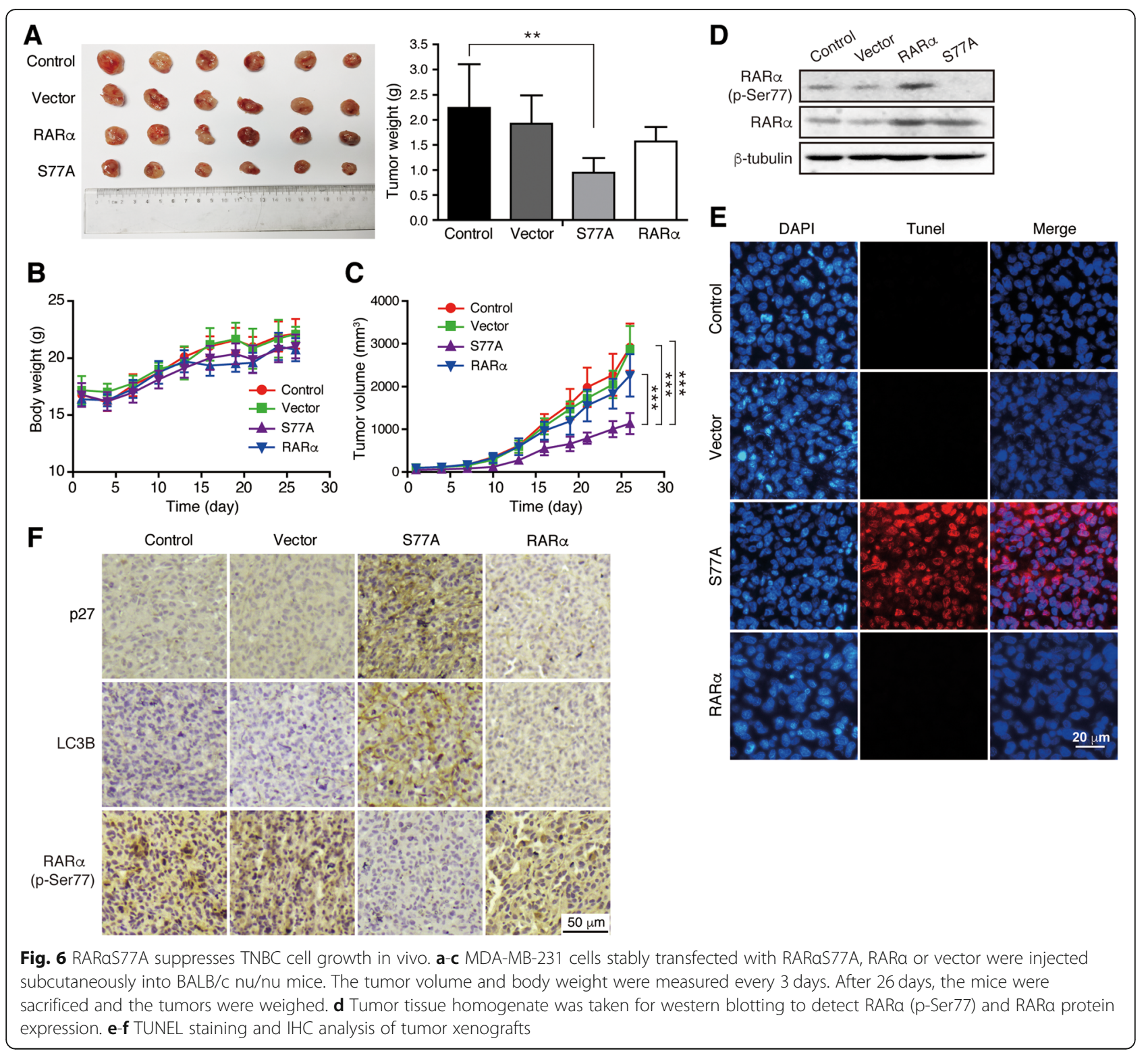

7c). Among these predicted targets, the dehydrogenase/ reductase member 3 (DHRS3, also known as retSDR1) was the candidate with the most likely predicted binding site and is known to be involved in maintaining the cellular supply of retinol metabolites [38, 39]. qRT-PCR and WB analysis confirmed that both RAR $\alpha$ S77A and miR-3074-5p decreased transcription and expression of DHRS3 (Fig. 7d). To further demonstrate that miR3074-5p directly regulates expression of DHRS3 mRNA through binding to its 3'UTR, wild-type (pmirGLODHRS3-3'UTR-wt) reporter vectors were co-transfected with either miR-3074-5p mimics or mimic-NC into 293FT cells. Luciferase activity of the 3'UTR construct of DHRS3 was attenuated by miR-3074-5p overexpression (Fig. 7e), thus suggesting that DHRS3 was a direct target of miR-3074-5p.

By using the online database Kaplan-Meier plotter, we found that DHRS3 is an unfavorable prognosis factor and is negatively associated with TNBC patients' overall survival (Fig. 7f). Therefore, by overexpressing DHRS3 in cells with hypo-phosphorylated RAR $\alpha$ S77 (Fig. 7g), we sought to investigate whether DHRS3 might offset the anti-tumor action of RAR$\alpha$ S77A. As expected, DHRS3 partially attenuated the proliferation-inhibitory effect of RAR $\alpha$ S77A (Fig. 7h, Supplemental Fig. 6). This pro-survival function of DHRS3 is presumably related to its reductase activity, as the overexpression of DHRS3 with a mutated 


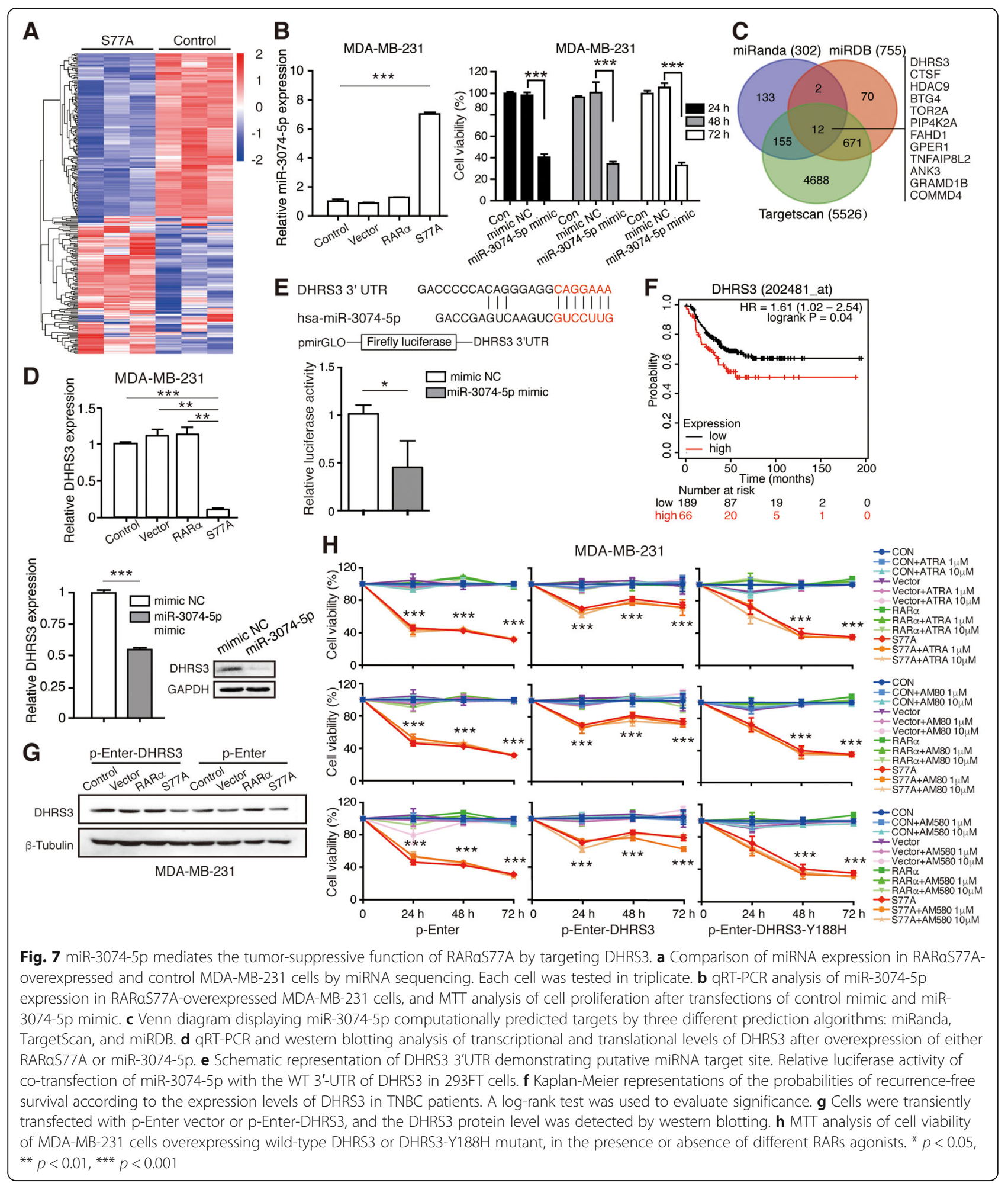

catalytic residue Tyr188 (DHRS3-Y188H) [39] failed to abolish RAR $\alpha$ S77A's action (Fig. 7h). Taken together, these findings indicate that miR-3074-5p mediated (at least in part) the tumor-suppressive effect of RAR $\alpha$ S77A by targeting DHRS3 in TNBC.

\section{CDK7 inhibitor THZ1 suppresses TNBC growth via RARaS77-DHRS3 signaling}

Because CDK7 is the major subunit of CAK complex responsible for phosphorylation of RAR $\alpha \mathrm{S} 77$ [40], we further addressed whether targeting CDK7 could be a 
treatment strategy to reduce phosphorylation of RAR $\alpha$ S77 in TNBC cells. As expected, a highly specific covalent CDK7 inhibitor THZ1 [41] markedly suppressed RAR $\alpha$ S77 phosphorylation as well as TNBC cell growth in vitro (Fig. 8a-b). This anti-tumor action of THZ1 may be attributed to the down-regulation of DHRS3 (Fig. 8c). Thus, targeting the phosphokinase of RAR $\alpha$ S77 may be a feasible approach to treat RAresistant TNBC.

\section{Discussion}

Study showed that a high proportion of Luminal/ER+ carcinomas are RA sensitive, while triple-negative (basal) tumors tend to be retinoid resistant [10]. One possible reason for this RA-resistance is the subcellular distribution of RA. The delivery of RA to RARs in the nucleus by cellular retinoic acid binding protein 2 (CRABP2) leads to inhibition of cell proliferation, apoptosis, invasion, and metastasis, whereas delivery of RA to peroxisome proliferator activated receptor beta (PPAR $\beta$ ) by FABP5 increases cell proliferation and causes RA resistance [42-44]. Higher expression of FABP5 is found in ER/PR-negative breast cancers, which competes with CRABP2 for RA ligand binding, and correlates with high histological grade and a poor prognosis [45]. Therefore, finding ways to activate RARs in a ligand-independent manner may bypass the unwanted pro-survival effect of RA. Here, we showed that RAR $\alpha 377$ A, a mutant that mimicked RAR $\alpha$ hypo-phosphorylation, could inhibit proliferation of TNBC both in vitro and in vivo. This antitumor effect was mediated by the induction of apoptosis, cell cycle arrest, and cytotoxic autophagy. Interestingly, RAR $\alpha$ S77A alone could activate RA-target gene transcription, while the addition of retinoids did not enhance RAR $\alpha$ S77A's efficacy (Figs. 2, 3, 4, 5 and 6). This is possibly due to the conformation change of RAR $\alpha$ where hypo-phosphorylated RAR $\alpha$ dissociated from transcriptional repressor and associated with coactivator [21]. Therefore, RAR $\alpha$ S77A functioned as an activated form of RAR $\alpha$ independent of RA stimulation, thus evading the pro-survival impact of RA on TNBC.

In this study, we explored the biological function of miR-3074-5p and its interaction with the RAR $\alpha$ signaling pathway in TNBC. Previously, miR-3074-5p was shown to be associated with favorable prognosis of papillary renal cell carcinoma patients [46], and acted primarily to inhibit cell proliferation and neuronal differentiation of oligodendrocyte precursors [47]. We found that RAR $\alpha$ S77A-induced transcription of miR-3074-5p inhibited TNBC cell proliferation, at least in part by directly targeting DHRS3 (Fig. 7). However, exactly how RAR$\alpha$ S77A regulated miR-3074-5p transcription remains to be determined. As RAR $\alpha$ is a known transcription factor that binds to RARE in the promoters of RA-target genes to modulate gene transcription [21], we suspect that RAR $\alpha$ S77A may activate miR-3074-5p transcription in a similar fashion. Indeed, in ER $\alpha+\mathrm{MCF}-7$ cells, liganddependent activation of RAR $\alpha$ increased its binding to the RARE regions of miR-21 promoter and enhanced miR-21 transcription [9]. Further research on the putative RARE binding sites of miR-3074-5p promoter by chromatin immunoprecipitation are warranted.

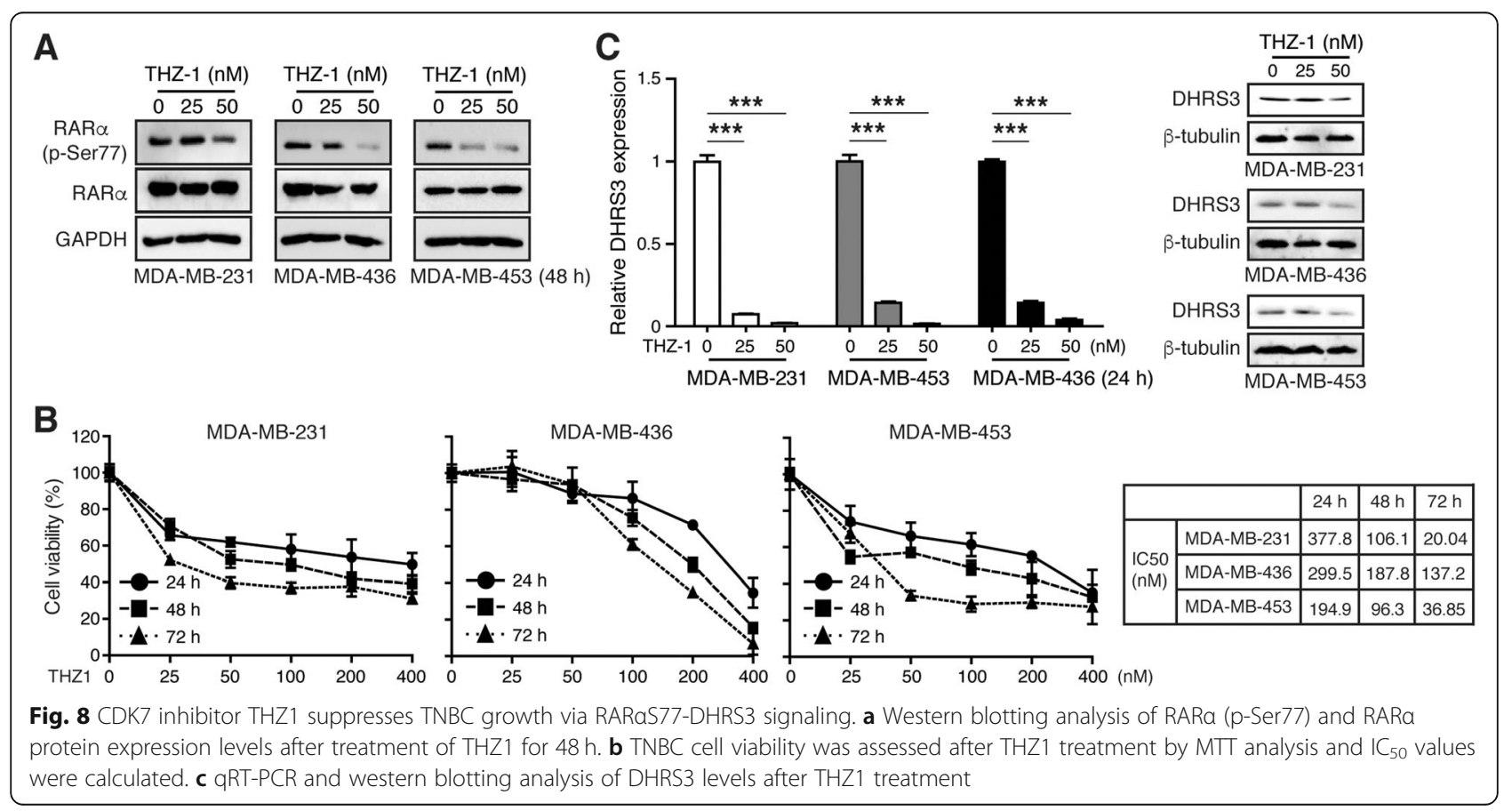


According to the miRNA microarray data, in addition to the transactivation of miR-3074-5p, RAR $\alpha$ S77A also upregulated tumor-suppressive miRNA such as miR-589$5 \mathrm{p}$, while down-regulated oncogenic miRNA such as miR-181a-3p (Supplemental Data). These altered miRNAs might have contributed to the anti-tumor action of RAR $\alpha$ S77A as well, thus explaining why miR-3074-5p's target DHRS3 only partially counteracted RAR $\alpha$ S77Ainduced growth arrest, and more work is required before we can fully understand the interplay between RAR $\alpha$ and these altered miRNAs.

This study also identified the molecular mechanism underlying miR-3074-5p's function in TNBC by discovering a direct target gene, DHRS3. DHRS3 is an enzyme strongly induced by RA in human neuroblastoma [48] and leukemic monocyte cell lines [49], which mainly catalyzes the reduction of all-transretinal, an opposite reaction of RA formation [39, 50]. However, the function of DHRS3 in TNBC and its association with RAR $\alpha$ remains poorly understood. We demonstrated here that DHRS3 is negatively correlated with TNBC patients' overall survival, which is consistent with the previous finding of frequent amplification of DHRS3 in the intermediate/high-risk group of papillary thyroid carcinomas [51], thus suggesting a potential oncogenic function of DHRS3. By transcriptional activation of miR-3074-5p that directly target DHRS3, RAR $\alpha$ S77A inhibited TNBC cell proliferation in vitro (Fig. 7). Nevertheless, our data hinted that DHRS3 may possess catalytic functions other than a retinal reductase, as the reduction of DHRS3 leading to possible elevated RA concentration did not enhance the antitumor action of RAR $\alpha$ S77A. Since DHRS3 also participated in the metabolism of other endogenous compounds, such as androstenedione, estrone, and DL-glyceraldehyde, and in the biotransformation of xenobiotics [52], it is reasonable to investigate this enzyme from another point of view in addition to its well-established functions, and more research is needed to clarify the exact role of DHRS3 in RAR $\alpha$ S77A-mediated anti-TNBC activity.

Our findings may have significant clinical implications for the development of anti-TNBC agents, by either mimicking the structure-conformation of hypophosphorylated RAR $\alpha \mathrm{S} 77$ or directly targeting its phosphokinase to overcome RA resistance, whereas miR-3074-5p and DHRS3 levels may also serve as potential diagnostic and/or prognostic markers and therapeutic targets in TNBC patients.

\section{Conclusions}

In summary, we demonstrated for the first time, that hyper-phosphorylation of RAR $\alpha \mathrm{S} 77$ is associated with RA-resistance while hypo-phosphorylated RAR $\alpha$ S77A functioned in an RA-independent manner to suppress TNBC progression in vitro and in vivo, by transactivating miR-3074-5p and reducing DHRS3. Our study provides new insights into the role and molecular mechanism of RAR $\alpha$ signaling in TNBC.

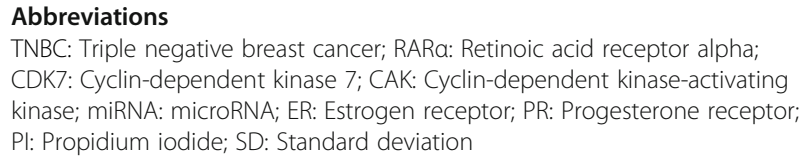

\section{Supplementary Information}

The online version contains supplementary material available at https://doi. org/10.1186/s13046-021-01941-7

Additional file 1: Supplemental Table 1. Association between RARa(p-Ser77) and clinical characteristic of breast cancer. Supplemental Figure 1. RARaS77 is constantly phosphorylated in MDA-MB-453 cells, which is associated with RA-resistance. Supplemental Figure 2. Lentiviral overexpression of RARaS77A and RARa in TNBC cells. Supplemental Figure 3. RARaS77A suppresses MDA-MB-453 cell growth in vitro. Supplemental Figure 4. RARaS77A induces cell cycle arrest and apoptosis in MDA-MB-453 cells. Supplemental Figure 5. RARaS77A induces cytotoxic-autophagy in MDA-MB-453 cells. Supplemental Figure 6. DHRS3 mediates the inhibitory effect of RARaS77A.

Additional file 2. Differential miRNAs.

\section{Acknowledgments}

We thank the tissue bank of Zhejiang Cancer Hospital for the patient specimens.

\section{Authors' contributions}

Funding acquisition, and conceptualization: S. Lou and H. Zhao. Investigation and data curation: H. Gao, H. Hong, and Z. Zhu. Writing-original draft and editing: S. Lou and H. Gao. The authors read and approved the final manuscript.

\section{Funding}

This work was supported by the National Natural Science Foundation of China (No. 81703549 and 81774003 )

\section{Availability of data and materials}

All data generated or analyzed during this study are included in this published article and its supplementary information files.

\section{Declarations}

Ethics approval and consent to participate

The current study was approved by the Institute Research Ethics Committee of the Zhejiang Cancer Hospital and performed in strict accordance with the Declaration of Helsinki. Written informed consent was obtained from each patient prior to enrollment. Extensive efforts were made to ensure minimal usage of animals as well as their suffering.

Consent for publication

Not applicable.

Competing interests

The authors declare that they have no competing interests.

Received: 23 February 2021 Accepted: 5 April 2021

Published online: 26 April 2021

\section{References}

1. Peddi PF, Ellis MJ, Ma C. Molecular basis of triple negative breast cancer and implications for therapy. Int J Breast Cancer. 2012;2012:217185. 
2. Davis SL, Eckhardt SG, Tentler JJ, Diamond JR. Triple-negative breast cancer: bridging the gap from cancer genomics to predictive biomarkers. Ther Adv Med Oncol. 2014;6(3):88-100. https://doi.org/10.1177/1758834013519843.

3. Bushue N, Wan YJ. Retinoid pathway and cancer therapeutics. Adv Drug Deliv Rev. 2010;62(13):1285-98. https://doi.org/10.1016/j.addr.2010.07.003.

4. Connolly RM, Nguyen NK, Sukumar S. Molecular pathways: current role and future directions of the retinoic acid pathway in cancer prevention and treatment. Clin Cancer Res. 2013;19(7):1651-9. https://doi.org/10.1158/10780432.CCR-12-3175.

5. Tang XH, Gudas LJ. Retinoids, retinoic acid receptors, and cancer. Annu Rev Pathol. 2011;6(1):345-64. https://doi.org/10.1146/annurev-pathol-011110-13 0303.

6. Warrell RP Jr, Frankel SR, Miller WH Jr, Scheinberg DA, Itri LM, Hittelman WN, et al. Differentiation therapy of acute promyelocytic leukemia with tretinoin (all-trans-retinoic acid). N Engl J Med. 1991;324(20):1385-93. https://doi.org/1 0.1056/NEJM199105163242002.

7. Huang ME, Ye YC, Chen SR, Chai JR, Lu JX, Zhoa L, et al. Use of all-trans retinoic acid in the treatment of acute promyelocytic leukemia. Blood. 1988; 72(2):567-72. https://doi.org/10.1182/blood.V72.2.567.567.

8. Petrie K, Zelent A, Waxman S. Differentiation therapy of acute myeloid leukemia: past, present and future. Curr Opin Hematol. 2009;16(2):84-91. https://doi.org/10.1097/MOH.0b013e3283257aee.

9. Terao M, Fratelli M, Kurosaki M, Zanetti A, Guarnaccia V, Paroni G, et al. Induction of miR-21 by retinoic acid in estrogen receptor-positive breast carcinoma cells: biological correlates and molecular targets. J Biol Chem. 2011;286(5):4027-42. https://doi.org/10.1074/jbc.M110.184994.

10. Centritto F, Paroni G, Bolis M, Garattini SK, Kurosaki M, Barzago MM, et al. Cellular and molecular determinants of all-trans retinoic acid sensitivity in breast cancer: luminal phenotype and RARa expression. EMBO Mol Med. 2015;7(7):950-72. https://doi.org/10.15252/emmm.201404670.

11. Wu L, Yee A, Liu L, Carbonaro-Hall D, Venkatesan N, Tolo VT, et al. Molecular cloning of the human CAK1 gene encoding a cyclin-dependent kinaseactivating kinase. Oncogene. 1994;9(7):2089-96.

12. Fisher RP, Morgan DO. A novel cyclin associates with MO15/CDK7 to form the CDK-activating kinase. Cell. 1994;78(4):713-24. https://doi.org/10.1016/ 0092-8674(94)90535-5.

13. Tassan JP, Jaquenoud M, Fry AM, Frutiger S, Hughes GJ, Nigg EA. In vitro assembly of a functional human CDK7-cyclin $\mathrm{H}$ complex requires MAT1, a novel 36 kDa RING finger protein. EMBO J. 1995;14(22):5608-17. https://doi. org/10.1002/j.1460-2075.1995.tb00248.x

14. Yee A, Nichols MA, Wu L, Hall FL, Kobayashi R, Xiong Y. Molecular cloning of CDK7-associated human MAT1, a cyclin-dependent kinase-activating kinase (CAK) assembly factor. Cancer Res. 1995;55(24):6058-62

15. Rochette-Egly C, Adam S, Rossignol M, Egly JM, Chambon P. Stimulation of RAR alpha activation function AF-1 through binding to the general transcription factor TFIIH and phosphorylation by CDK7. Cell. 1997;90(1):97107. https://doi.org/10.1016/S0092-8674(00)80317-7.

16. Bastien J, Rochette-Egly C. Nuclear retinoid receptors and the transcription of retinoid-target genes. Gene. 2004;328:1-16. https://doi.org/10.1016/j. gene.2003.12.005.

17. Crowe DL, Kim R. A phosphorylation defective retinoic acid receptor mutant mimics the effects of retinoic acid on EGFR mediated AP-1 expression and cancer cell proliferation. Cancer Cell Int. 2002;2(1):15. https://doi.org/10.11 86/1475-2867-2-15

18. Wang J, Barsky LW, Shum CH, Jong A, Weinberg Kl, Collins SJ, et al. Retinoid-induced G1 arrest and differentiation activation are associated with a switch to cyclin-dependent kinase-activating kinase hypophosphorylation of retinoic acid receptor alpha. J Biol Chem. 2002;277(45):43369-76. https:// doi.org/10.1074/jbc.M206792200.

19. Zhang S, He Q, Peng H, Tedeschi-Blok N, Triche TJ, Wu L. MAT1-modulated cyclin-dependent kinase-activating kinase activity cross-regulates neuroblastoma cell G1 arrest and neurite outgrowth. Cancer Res. 2004;64(9): 2977-83. https://doi.org/10.1158/0008-5472.CAN-03-4018.

20. Luo $P$, Yang $X$, Ying M, Chaudhry $P$, Wang $A$, Shimada $H$, et al. Retinoidsuppressed phosphorylation of RARalpha mediates the differentiation pathway of osteosarcoma cells. Oncogene. 2010;29(19):2772-83. https://doi. org/10.1038/onc.2010.50

21. Wang A, Alimova IN, Luo P, Jong A, Triche TJ, Wu L. Loss of CAK phosphorylation of RAR \{alpha\} mediates transcriptional control of retinoidinduced cancer cell differentiation. FASEB J. 2010;24(3):833-43. https://doi. org/10.1096/fj.09-142976.
22. Bartel DP. MicroRNAs: genomics, biogenesis, mechanism, and function. Cell. 2004;116(2):281-97. https://doi.org/10.1016/S0092-8674(04)00045-5.

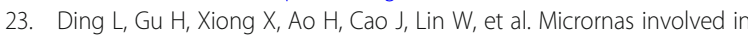
Carcinogenesis, Prognosis, therapeutic resistance and applications in human triple-negative breast cancer. Cells. 2019;8(12):1492.

24. Lee DY, Lin TE, Lee Cl, Zhou J, Huang YH, Lee PL, et al. MicroRNA-10a is crucial for endothelial response to different flow patterns via interaction of retinoid acid receptors and histone deacetylases. Proc Natl Acad Sci U S A. 2017;114(8):2072-7. https://doi.org/10.1073/pnas.1621425114.

25. Weiss FU, Marques IJ, Woltering JM, Vlecken DH, Aghdassi A, Partecke LI, et al. Retinoic acid receptor antagonists inhibit miR-10a expression and block metastatic behavior of pancreatic cancer. Gastroenterology. 2009; 137(6):2136-45

26. Peng $Y$, Zhang $X$, Ma Q, Yan R, Qin Y, Zhao $Y$, et al. MiRNA-194 activates the Wnt/B-catenin signaling pathway in gastric cancer by targeting the negative Wnt regulator, SUFU. Cancer Lett. 2017;385:117-27. https://doi. org/10.1016/j.canlet.2016.10.035.

27. Yang B, Zhu R, Tian S, Wang Y, Lou S, Zhao H. Jatamanvaltrate P induces cell cycle arrest, apoptosis and autophagy in human breast cancer cells in vitro and in vivo. Biomed Pharmacother. 2017;89:1027-36.

28. Falanga A, Consonni R, Marchetti M, Locatelli G, Garattini E, Passerini CG et al. Cancer procoagulant and tissue factor are differently modulated by all-trans-retinoic acid in acute promyelocytic leukemia cells. Blood. 1998; 92(1):143-51. https://doi.org/10.1182/blood.V92.1.143.413k18_143_151.

29. Gianní M, Li Calzi M, Terao M, Guiso G, Caccia S, Barbui T, et al. AM580, a stable benzoic derivative of retinoic acid, has powerful and selective cytodifferentiating effects on acute promyelocytic leukemia cells. Blood. 1996;87(4): 1520-31. https://doi.org/10.1182/blood.V87.4.1520.bloodjournal8741520.

30. Liu M, lavarone A, Freedman LP. Transcriptional activation of the human p21(WAF1/CIP1) gene by retinoic acid receptor. Correlation with retinoid induction of U937 cell differentiation. J Biol Chem. 1996;271(49):31723-8. https://doi.org/10.1074/jbc.271.49.31723.

31. Donato LJ, Noy N. Suppression of mammary carcinoma growth by retinoic acid: proapoptotic genes are targets for retinoic acid receptor and cellular retinoic acid-binding protein II signaling. Cancer Res. 2005;65(18):8193-9. https://doi.org/10.1158/0008-5472.CAN-05-1177.

32. Park DJ, Chumakov AM, Vuong PT, Chih DY, Gombart AF, Miller WH Jr, et al. CCAAT/enhancer binding protein epsilon is a potential retinoid target gene in acute promyelocytic leukemia treatment. J Clin Invest. 1999;103(10):1399408. https://doi.org/10.1172/JCl2887.

33. de Thé $H$, Vivanco-Ruiz MM, Tiollais $P$, Stunnenberg $H$, Dejean A. Identification of a retinoic acid responsive element in the retinoic acid receptor beta gene. Nature. 1990;343(6254):177-80. https://doi.org/10.103 8/343177a0.

34. Loudig O, Babichuk C, White J, Abu-Abed S, Mueller C, Petkovich M. Cytochrome P450RAI(CYP26) promoter: a distinct composite retinoic acid response element underlies the complex regulation of retinoic acid metabolism. Mol Endocrinol. 2000;14(9):1483-97.

35. Wang JG, Barsky LW, Davicioni E, Weinberg Kl, Triche TJ, Zhang XK, et al. Retinoic acid induces leukemia cell G1 arrest and transition into differentiation by inhibiting cyclin-dependent kinase-activating kinase binding and phosphorylation of PML/RARalpha. FASEB J. 2006;20(12):21424. https://doi.org/10.1096/fj.06-5900fje.

36. Brigger D, Schläfli AM, Garattini E, Tschan MP. Activation of RARa induces autophagy in SKBR3 breast cancer cells and depletion of key autophagy genes enhances ATRA toxicity. Cell Death Dis. 2015;6(8):e1861. https://doi. org/10.1038/cddis.2015.236.

37. Wang J, Lin Z, Yang Z, Liu X. IncRNA Eif4g2 improves palmitate-induced dysfunction of mouse $\beta$-cells via modulation of Nrf2 activation. Exp Cell Res. 2020;396(2):112291.

38. Kam RK, Shi W, Chan SO, Chen Y, Xu G, Lau CB, et al. Dhrs3 protein attenuates retinoic acid signaling and is required for early embryonic patterning. J Biol Chem. 2013;288(44):31477-87. https://doi.org/10.1074/jbc. M113.514984.

39. Haeseleer F, Huang J, Lebioda L, Saari JC, Palczewski K. Molecular characterization of a novel short-chain dehydrogenase/reductase that reduces all-trans-retinal. J Biol Chem. 1998;273(34):21790-9. https://doi.org/1 0.1074/jbc.273.34.21790.

40. Bour G, Gaillard E, Bruck N, Lalevee S, Plassat JL, Busso D, et al. Cyclin H binding to the RARalpha activation function (AF)-2 domain directs phosphorylation of the AF-1 domain by cyclin-dependent kinase 7. Proc 
Natl Acad Sci U S A. 2005;102(46):16608-13. https://doi.org/10.1073/pnas. 0505556102.

41. Kwiatkowski N, Zhang T, Rahl PB, Abraham BJ, Reddy J, Ficarro SB, et al. Targeting transcription regulation in cancer with a covalent CDK7 inhibitor. Nature. 2014;511(7511):616-20. https://doi.org/10.1038/nature13393.

42. Schug TT, Berry DC, Shaw NS, Travis SN, Noy N. Opposing effects of retinoic acid on cell growth result from alternate activation of two different nuclear receptors. Cell. 2007;129(4):723-33. https://doi.org/10.1016/..cell.2007.02.050.

43. Schug TT, Berry DC, Toshkov IA, Cheng L, Nikitin AY, Noy N. Overcoming retinoic acid-resistance of mammary carcinomas by diverting retinoic acid from PPARbeta/delta to RAR. Proc Natl Acad Sci U S A. 2008;105(21):754651. https://doi.org/10.1073/pnas.0709981105.

44. Noy N. Between death and survival: retinoic acid in regulation of apoptosis. Annu Rev Nutr. 2010;30(1):201-17. https://doi.org/10.1146/annurev.nutr.28. 061807.155509.

45. Liu RZ, Graham K, Glubrecht DD, Germain DR, Mackey JR, Godbout R. Association of FABP5 expression with poor survival in triple-negative breast cancer: implication for retinoic acid therapy. Am J Pathol. 2011;178(3):9971008. https://doi.org/10.1016/j.ajpath.2010.11.075.

46. Ge YZ, Xu LW, Xu Z, Wu R, Xin H, Zhu M, et al. Expression profiles and clinical significance of MicroRNAs in papillary renal cell carcinoma: a STROBE-compliant observational study. Medicine. 2015;94(16):e767. https:// doi.org/10.1097/MD.0000000000000767.

47. Yang J, Xiong LL, Wang YC, He X, Jiang L, Fu SJ, et al. Oligodendrocyte precursor cell transplantation promotes functional recovery following contusive spinal cord injury in rats and is associated with altered microRNA expression. Mol Med Rep. 2018;17(1):771-82. https://doi.org/10.3892/mmr.2 017.7957.

48. Cerignoli F, Guo X, Cardinali B, Rinaldi C, Casaletto J, Frati L, et al. retSDR1, a short-chain retinol dehydrogenase/reductase, is retinoic acid-inducible and frequently deleted in human neuroblastoma cell lines. Cancer Res. 2002; 62(4):1196-204.

49. Zolfaghari R, Chen Q, Ross AC. DHRS3, a retinal reductase, is differentially regulated by retinoic acid and lipopolysaccharide-induced inflammation in THP-1 cells and rat liver. Am J Physiol Gastrointest Liver Physiol. 2012;303(5): G578-88. https://doi.org/10.1152/ajpgi.00234.2012.

50. Blomhoff R, Blomhoff HK. Overview of retinoid metabolism and function. J Neurobiol. 2006;66(7):606-30. https://doi.org/10.1002/neu.20242.

51. Passon N, Bregant E, Sponziello M, Dima M, Rosignolo F, Durante C, et al. Somatic amplifications and deletions in genome of papillary thyroid carcinomas. Endocrine. 2015;50(2):453-64. https://doi.org/10.1007/s12020-01 5-0592-z.

52. Lundová T, Zemanová L, Malčeková B, Skarka A, Štambergová H, Havránková J, et al. Molecular and biochemical characterisation of human short-chain dehydrogenase/reductase member 3 (DHRS3). Chem Biol Interact. 2015;234:178-87. https://doi.org/10.1016/j.cbi.2014.10.018.

\section{Publisher's Note}

Springer Nature remains neutral with regard to jurisdictional claims in published maps and institutional affiliations.

Ready to submit your research? Choose BMC and benefit from:

- fast, convenient online submission

- thorough peer review by experienced researchers in your field

- rapid publication on acceptance

- support for research data, including large and complex data types

- gold Open Access which fosters wider collaboration and increased citations

- maximum visibility for your research: over $100 \mathrm{M}$ website views per year

At $\mathrm{BMC}$, research is always in progress.

Learn more biomedcentral.com/submissions 